\title{
Estimación del coste de la atención a la dependencia en centros residenciales y de atención diurna o nocturna
}

\section{Belén Díaz Díaz}

Dpto. de Administración de Empresas, Universidad de Cantabria

<belen.diaz@unican.es>

Kantabriako mendeko pertsonei arreta eskaintzen dieten egoitza eta eguneko zentroen kostu-eredu bat definitzeko ahalegina jasotzen da azterlan honetan. Horren bidez, ahalbidetu nahi dira politikak eta hitzartutako ekimenak, betiere kontuan hartuz eginkizun horien kostuak zeintzuk diren. Eredua aztertu da zentroa, erabiltzailearen mendekotasunmaila, zentroaren tamaina eta arreta zuzeneko datuak eta balizko egoerak aztertuz, eta horrek ahalbidetuko omen du banan-banako kasuetan kostu teoriko bat definitzen. 50,15 eta 64,98 euro inguru kostatzen da plaza bat arreta zuzeneko 0,36 ko ratio baterako, eta horrek erakusten du administrazioek eskainitako finantzazioaren \%90 eta \%70aren tarteko bataz bestekoa betetzen dutela plaza bakoitzeko. Eguneko edo gaueko plaza baten kostua 27,39 eta 35,16 eurotakoa da 0,19ko arreta zuzeneko ratio batean.

\section{HITZ-GAKOAK:}

mendekotasunaren arreta, bizitzeko zentroak, egun/ gaueko zentroak, kostuak, hitzartutako politika.
Este trabajo pretende definir un modelo de costes en las residencias y centros de atención a personas dependientes de Cantabria que permita definir políticas y acciones de concertación, y que tenga en cuenta todos los costes necesarios para el ejercicio de la actividad. El modelo se ha aplicado a distintos escenarios, en función del tipo de centro, el grado de dependencia de los usuarios, el tamaño del centro y la ratio de atención directa, y permitirá establecer el coste teórico en cada caso. El coste en atención residencial oscila entre 50,15 y 64,98 euros/plaza para una ratio de atención directa de 0,36 , lo que representa entre el $90 \%$ y el $70 \%$ de la media ofrecida por las administraciones por plaza concertada. El coste en atención diurna o nocturna oscila entre 27,39 y 35,16 euros/plaza para una ratio de atención directa de 0,19.

\section{PALABRAS CLAVE:}

atención a la dependencia, centros residenciales, centros de día/noche, costes, política de concertación. 


\section{Introducción}

Desde hace décadas, Europa y España están viviendo un importante cambio demográfico, caracterizado por el envejecimiento de la población, la reducción de la natalidad y la internacionalización de la población a través de procesos migratorios. En este contexto, la atención a las personas en situación de dependencia y la promoción de su autonomía personal constituye uno de los principales temas de política social de los países desarrollados. En particular, el número de personas dependientes previsto para 2015 en España se cifra en 1.373 .248 , lo que supone un incremento del $22 \%$ respecto a 2005 (Deloitte, 2008).

Con la aprobación de la Ley 39/2006, de 14 de diciembre, de Promoción de la Autonomía Personal y Atención a las Personas en Situación de Dependencia, y la Ley cántabra 2/2007, de 27 de marzo, de Derechos y Servicios Sociales, se garantiza la atención y cuidados a las personas en situación de dependencia. Ambas leyes centran una importante parte de su articulado en los sistemas de calidad de los centros de atención a la dependencia, incidiendo de forma especial en la profesionalidad de las personas responsables de la prestación de la asistencia y en la mejora de su cualificación, lo que supondrá inevitablemente un incremento en los costes que supone este tipo de actividad ${ }^{1}$.

Sin embargo, sin un conocimiento de todos los costes que implican estas actividades no será posible establecer políticas de concertación que garanticen la sostenibilidad del sistema. Estudios previos han mostrado resultados distintos en relación con la cuantificación de los costes, dependiendo de las variables incluidas en dicha cuantificación, el tipo de servicio analizado (mayoritariamente residencial) e incluso el ámbito geográfico donde se ha realizado el estudio.

Este estudio se centrará en dos servicios de atención a la dependencia que, por su demanda, tienen un interés especial: la atención residencial (que solicitan el $85,3 \%$ de los gran dependientes y el $35,5 \%$ de los dependientes severos), y los centros de día y noche (que demandan el 5,1\% de los gran dependientes y el $18,3 \%$ de los dependientes severos [Deloitte, 2008]). Por lo tanto, el objetivo de este trabajo será definir un modelo de costes en las residencias y centros de atención a personas dependientes en el ámbito geográfico de la comunidad autónoma de Cantabria que permita definir políticas y acciones de concertación, y que tenga en cuenta todos los costes necesarios para el ejercicio de la actividad. El modelo de costes permitirá establecer el coste teórico de la atención a las necesidades de las diferentes tipologías de personas

${ }^{1}$ En particular, el artículo 81.3 de la Ley 2/2007 establece que "todos los centros y entidades, tanto públicos como privados, de servicios sociales estarán obligados a realizar, periódicamente, una evaluación interna de calidad de los servicios prestados, a excepción hecha de los centros residenciales que cuenten con más de cien plazas, concertadas o no, que estarán obligados a contar con un sistema de gestión de la calidad certificado por un organismo acreditado a tal efecto". en situación de dependencia en los diferentes tipos de centros de atención, y la metodología utilizada podría ser extrapolada a otras regiones.

Durante la recogida y el posterior análisis de la información necesaria para llevar a cabo el estudio, se ha podido extraer una primera conclusión que debe señalarse para, en primer lugar, poner de relieve la complejidad del sector y, en segundo, manifestar la necesidad de profesionalizar la gestión de estos centros: las empresas de atención a la dependencia constituyen un sector complejo y diverso, donde la información sobre su funcionamiento y sus costes resulta, en algunas ocasiones, difícil de obtener, y en otras, los datos obtenidos parecen no responder a la realidad.

En este contexto, la elaboración de un modelo de costes único para todas las empresas de atención a la dependencia resulta complicada, ya que cada empresa presenta particularidades concretas que conducirían a la elaboración de un modelo de costes individual para cada centro. Sin embargo, esto no permitiría tener una referencia con la que establecer políticas y acciones de concertación para atender a las personas en situación de dependencia, y se plantea la necesidad de establecer estándares, en la medida de lo posible, para cuantificar los recursos humanos y materiales utilizados para el desarrollo de la actividad. Por ello, a lo largo del estudio se irá depurando la muestra objeto de análisis, se irán adoptando hipótesis sobre algunos costes asumidos y se irán considerando distintos escenarios posibles.

\section{Muestra objeto de estudio y escenarios para el cálculo de costes}

La muestra objeto de estudio está constituida por el universo de centros de atención a la dependencia de la región de Cantabria (incluyendo tanto la atención a mayores como a discapacitados). De acuerdo con la información suministrada por la Dirección General de Políticas Sociales del Gobierno de Cantabria, en la comunidad autónoma existen un total de 152 centros concertados de atención a la dependencia, que se elevan a 160 si se incluyen los no concertados. El total de plazas autorizadas asciende a 8.627, de las que el $63 \%$ son en residencias para mayores y un $13,79 \%$ en centros de día para mayores, de manera que casi el $77 \%$ de las plazas están vinculadas con personas mayores.

Para poder desarrollar el modelo de costes, se ha recurrido al análisis de tres fuentes de información:

- Las experiencias y trabajos realizados en España en los últimos años sobre modelos de costes en centros de atención a personas dependientes, que ofrecen conocimientos y metodologías contrastadas susceptibles de aumentar la eficacia del modelo (BIC Galicia, 2008; Deloitte, 2006; Centro Europeo de Empresas e Innovación de Navarra, 2003; Montserrat, 2005; Guillén, 2007; Deloitte, 2008; entre otros). 
- La información cuantitativa recogida a través de cuestionario a los responsables de los centros, que permite establecer una fuente primaria real de información sobre la que apoyar el modelo de costes. La recogida de datos se realizó durante el segundo semestre de 2008 , con un total de 68 respuestas y un coeficiente de respuesta de un $44,7 \%$.

- La normativa vigente sobre la promoción de la autonomía personal y la atención a personas en situación de dependencia.

El modelo de costes ha sido aplicado a distintos escenarios en función del tipo de centro, el grado de dependencia de los usuarios, el tamaño del centro y la ratio de atención directa, como refleja la Tabla 1 y se explica a continuación.

Tabla 1. Escenarios para el modelo de costes

\begin{tabular}{|c|c|c|c|}
\hline Variable & \multicolumn{3}{|c|}{ Escenarios para el modelo de costes } \\
\hline Tipo de centro & Residencial & \multicolumn{2}{|c|}{$\begin{array}{c}\text { De atención diurna o } \\
\text { nocturna }\end{array}$} \\
\hline № centros & 37 & \multicolumn{2}{|r|}{31} \\
\hline $\begin{array}{l}\text { Grado de } \\
\text { dependencia }\end{array}$ & Moderada & Severa & $\begin{array}{c}\text { Gran } \\
\text { dependencia }\end{array}$ \\
\hline № centros & 24 & 12 & 24 \\
\hline $\begin{array}{l}\text { Tamaño del } \\
\text { centro }\end{array}$ & 50 plazas & $\begin{array}{l}50-100 \\
\text { plazas }\end{array}$ & $>100$ plazas \\
\hline № centros & 42 & 14 & 12 \\
\hline $\begin{array}{l}\text { Ratio de } \\
\text { atención directa }\end{array}$ & \multicolumn{3}{|c|}{$\begin{array}{l}\text { Con variaciones de } 0,05 \text {, desde una ratio de 0,36 } \\
\text { para atención residencial y una de o,19 para } \\
\text { atención diurna/nocturna }\end{array}$} \\
\hline
\end{tabular}

Fuente: Elaboración propia.

\subsection{Tipo de centro}

Inicialmente, se clasificaron los centros de acuerdo con el catálogo de servicios que establece la Ley 39/2006 de Promoción de la Autonomía Personal y Atención a las Personas en Situación de Dependen$\mathrm{cia}^{2}$. Sin embargo, la evidencia mostró que el mismo centro podía estar dentro de varias tipologías, al ofrecer varios de los servicios contemplados a la vez (incluso ser centro de atención diurna o nocturna y residencial al mismo tiempo).

Por lo tanto, para poder establecer una clasificación de los centros en una única categoría se optó por dos criterios:

${ }^{2}$ El artículo 15 de la ley establece el catálogo de servicios, que distingue entre el servicio de centro de día y de noche (categoría dentro de la cual están el centro de día para mayores, el centro de día para menores de 65 años, el centro de día de atención especializada y el centro de noche) y el servicio de atención residencial (dentro del cual se diferencia entre la residencia de personas mayores en situación de dependencia y el centro de atención a personas en situación de dependencia, en razón de los distintos tipos de discapacidad).
- Clasificar los centros según sean centros de atención residencial (aunque puedan realizar atención diurna y nocturna) o centros de atención diurna o nocturna exclusivamente (en la mayoría de los casos, se trata de centros de día o centros ocupacionales).

- Clasificar los centros de acuerdo con el servicio que ofrecen mayoritariamente a sus usuarios, sean personas mayores o con discapacidad, aunque residualmente tengan usuarios del otro grupo.

\subsection{Grado de dependencia de los usuarios}

De acuerdo con el artículo 26 de la Ley 39/2006, se han establecido tres grados de dependencia: moderada, severa y gran dependencia3 . Dado que un mismo centro puede ofrecer cobertura para distintos grados de dependencia, la clasificación se ha realizado considerando el grado de dependencia que mayoritariamente tienen sus usuarios. El grado de dependencia, como se ha observado en otros estudios (Deloitte, 2006), afecta al coste de una plaza.

\subsection{Tamaño (número de plazas)}

Se realizó una clasificación de los centros según el número de plazas ofertadas en tres grupos: con menos de 50 plazas, con entre 50 y 100, y con más de 100 plazas. La evidencia ha demostrado que el tamaño del centro tiene un efecto directo sobre sus costes y su rentabilidad, puesto que a partir de un determinado número de plazas puede haber costes marginales decrecientes por la obtención de economías de escala.

El corte en 50 plazas se realiza por dos motivos:

- Porque se trata del grupo mayoritario entre las residencia tipo, tanto en Cantabria como en otras comunidades autónomas como Galicia (BIC Galicia, 2008).

- Porque aquellos centros con menos de 50 plazas no son rentables o son poco rentables, por término medio. De hecho, el Centro Europeo de Empresas e Innovación de Navarra (2003) plantea que no es recomendable crear una residencia con menos de 50 plazas y Magariño (2006) establece que los costes de inversión y de mantenimiento de un centro residencial resultan tan elevados que, para sacar rentabilidad a la inversión, deberían ofrecerse entre 70 y 100 plazas.

El corte en las 100 plazas se realiza básicamente por la obligación que establece la Ley 2/2007 de que estos centros cuenten con sistemas de gestión de la calidad certificados por un organismo acreditado al

${ }^{3}$ Estos grados de dependencia se mantienen en el Decreto Ley de 13 de julio de 2012, aunque desaparecen los dos niveles que la Ley $39 / 2006$ establecía para cada grado. 

agosto, por la que se regulan los requisitos materiales y funcionales de los centros de servicios sociales especializados en Cantabria, establece determinados requisitos de espacio por cada 500100 plazas $^{4}$.

\subsection{Intensidad con la que se presta el servicio ( $n$ o de profesionales / $\mathrm{n}$ ㅇ de plazas)}

Un incremento en los recursos humanos que trabajan en el centro, para ajustarse a las ratios de atención directa que marque la legislación vigente, provocará inevitablemente un incremento en los costes. Este punto se desarrolla más detalladamente en el apartado 6.2, destinado a los costes de personal. Asimismo, se utilizaron otros dos criterios de clasificación, que finalmente fueron descartados: la ubicación geográfica, y el tipo de propiedad y las condiciones de explotación.

En cuanto a la ubicación, se han distinguido cuatro zonas dentro de Cantabria: zona Santander-arco de la bahía, zona occidental-centro, zona oriental y zona sur. También se ha diferenciado el entorno en el que se encuentra el centro, según sea casco urbano, zona rural, zona periférica del centro de una urbe $u$ otra zona. A priori, cabe pensar que la ubicación del centro puede afectar al coste a través de su influencia sobre los costes de inversión en inmuebles o terrenos, lo que llevaría a generar distintos escenarios de costes según su ubicación. Sin embargo, teniendo en cuenta los datos que sobre el coste del inmueble y del terreno suministraron los centros encuestados, no existen diferencias estadísticamente significativas al distinguir por zona geográfica, ni por entorno en el que se encuentra el centro.

En relación con el tipo de propiedad, se clasificó a los centros en públicos y privados, distinguiéndose entre los primeros los centros con explotación privada en gestión y en concesión. Si bien esta clasificación ha permitido obtener costes diferenciados en otros estudios (Deloitte, 2006)5, no permite establecer una clasificación representativa en el caso de Cantabria, ya que únicamente dos centros son de titularidad pública. efecto. Asimismo, la Orden EMP/68/2008, de 27 de

\section{Metodología de trabajo}

Para elaborar el modelo de costes, ha sido necesario desarrollar los siguientes pasos:

1. Determinar el modelo de costes: este modelo se plantea de manera flexible, ya que, como se comentó anteriormente, la tipología de los centros de atención a la dependencia es variada y se considera adecuado plantear distintos escenarios posibles en función del: tipo de centro, el grado de dependencia de los usuarios, el tamaño del centro y la ratio de atención directa.

- Tipo de centro (residencial o de atención diurna o nocturna; centros para mayores o centros para discapacitados).

- Grado de dependencia de los usuarios, distinguiéndose los tres grados que marca la Ley 39/2006.

- Tamaño del centro según número de plazas, distinguiéndose tres tamaños (menos de 50 plazas, entre 50 y 100 plazas y más de 100 plazas).

- Ratio de atención directa que se preste a los usuarios por parte de los profesionales.

2. Plantear las hipótesis utilizadas: se han identificado trece variables para elaborar el modelo de costes, que en algunos casos se han construido a través del cálculo o la consideración de otras ocho variables.

3. Contrastar las hipótesis utilizadas: se han buscado las fuentes de información que han permitido contrastar que las hipótesis planteadas son coherentes y fiables.

4. Calcular el modelo de costes: con un modelo único, se han calculado los costes para cada uno de los distintos escenarios planteados.

\section{Estudio de las variables utilizadas}

La Tabla 2 resume las variables incluidas en el modelo de costes, cuyo detalle se explica en los apartados siguientes.

Además de las doce variables de costes, reflejadas en la Tabla 2, se tiene en cuenta la variable 'ocupación de los centros’ que resulta necesaria para poder estimar los costes variables.

\section{Inversión inicial}

(2006) distingue dos tamaños: 90 plazas y 150 plazas; y BIC Galici (2008) diferencia minirresidencias (13-59 plazas), residencias (60-120 plazas) y grandes centros residenciales (más de 120 plazas).

${ }_{5}$ El estudio de Deloitte (2008), realizado para 63 centros de 13 comunidades autónomas, permite distinguir mayores costes diarios por plaza en aquellos casos en que la explotación es privada en propiedad, frente a los centros públicos que tienen concesión o gestión privada. En particular, para centros de 90 plazas se observa un coste promedio diario por plaza de 44,40 € para el caso de explotación en gestión, 57,21 € para concesión y 62,96 € para propiedad. Para centros de 150 plazas, el coste promedio diario por plaza es de 41,16 € para el caso de explotación en gestión, 53,97 € para concesión y 59,86 € para propiedad.

\subsection{Superficie construida por usuario y coste de construcción}

La inversión necesaria para la puesta en marcha de un centro de atención a la dependencia resulta elevada, principalmente por el gasto en edificación (obra nueva o rehabilitación de una existente). Este coste debe tenerse en cuenta a la hora de calcular 


\begin{tabular}{|c|c|c|}
\hline Coste & Variables & Fuente utilizada \\
\hline $\begin{array}{l}\text { Depreciación } \\
\text { de inmuebles y } \\
\text { equipamiento }\end{array}$ & $\begin{array}{l}\text { Donde, } \\
\text { coste en inmuebles y equipamiento por plaza = } \\
\text { superficie construida por usuario x coste } \mathrm{m}^{2} \\
\text { Para su cálculo se tienen en cuenta } 4 \text { variables: } \\
\text { - Superficie construida }\left(\mathrm{m}^{2} / \text { plaza) }\right. \\
\text { - Coste por } \mathrm{m}^{2} \text { en edificación y equipamiento } \\
\text { - Estructura de la inversión inicial } \\
\text { - Plazo de amortización }\end{array}$ & $\begin{array}{l}\text { - Cuestionario a responsables de los centros } \\
\text { - Entrevistas con operadores del sector } \\
\text { - Estudios de costes previamente elaborados* } \\
\text { - Boletín Económico de la Construcción ( } 2^{\circ} \text { trimestre } \\
\text { 2008) } \\
\text { - Orden EMP/68/2008, de } 27 \text { de agosto }\end{array}$ \\
\hline $\begin{array}{l}\text { Coste de personal de } \\
\text { atención directa }\end{array}$ & $\begin{array}{l}\text { Ratio de atención directa x sueldo anual }+33 \% \\
\text { seguridad social } \\
\text { Para su cálculo, se tienen en cuenta cuatro variables: } \\
\text { - № de trabajadores equivalentes al año } \\
\text { - Ratio de plazas sobre trabajadores } \\
\text { - Estructura de personal } \\
\text { - Sueldo anual }\end{array}$ & $\begin{array}{l}\text { - Cuestionario a responsables de los centros } \\
\text { - Estudios de costes previamente elaborados* } \\
\text { - V Convenio Colectivo Marco Estatal de Servicios de } \\
\text { Atención a Personas Dependientes y Desarrollo de la } \\
\text { Promoción Personal (2008) }\end{array}$ \\
\hline $\begin{array}{l}\text { Costes adicionales de } \\
\text { personal }\end{array}$ & \% sobre el coste de personal & $\begin{array}{l}\text { - Cuestionario a responsables de los centros } \\
\text { - Estudios de costes previamente elaborados* }\end{array}$ \\
\hline Coste de manutención & Coste de manutención por plaza y día & 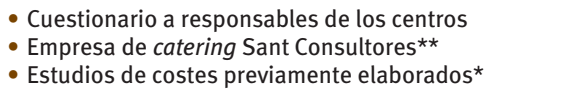 \\
\hline $\begin{array}{l}\text { Coste de } \\
\text { mantenimiento y } \\
\text { suministro }\end{array}$ & Coste de mantenimiento y suministro por $\mathrm{m}^{2}$ & - Cuestionario a responsables de los centros \\
\hline Coste de limpieza & Coste de limpieza por plaza y año & - Cuestionario a responsables de los centros \\
\hline $\begin{array}{l}\text { Coste en seguros y } \\
\text { seguridad }\end{array}$ & Coste en seguros y seguridad por plaza y año & - Cuestionario a responsables de los centros \\
\hline $\begin{array}{l}\text { Coste en viajes y } \\
\text { traslados }\end{array}$ & Coste en viajes por plaza y año & - Cuestionario a responsables de los centros \\
\hline Servicios de gestión & Coste en servicios de gestión por plaza y año & - Cuestionario a responsables de los centros \\
\hline $\begin{array}{l}\text { Implantación de } \\
\text { sistemas de gestión de } \\
\text { la calidad }\end{array}$ & $\%$ sobre el coste total operativo & $\begin{array}{l}\text { - Cuestionario a responsables de los centros } \\
\text { - Guillén (2007) }\end{array}$ \\
\hline Costes financieros & \% sobre la inversión inicial & $\begin{array}{l}\text { - Cuestionario a responsables de los centros } \\
\text { - Evolución del euríbor a } 12 \text { meses }\end{array}$ \\
\hline Margen de beneficios & $\%$ sobre el coste total operativo & $\begin{array}{l}\text { - Cuestionario a responsables de los centros } \\
\text { - Estudios de costes previamente elaborados* }\end{array}$ \\
\hline
\end{tabular}

*Vid. supra. ${ }^{\star \star}$ Consulta directa con la empresa.

Fuente: Elaboración propia.

el coste por plaza del centro, ya que esta inversión inicial se irá deteriorando y amortizando con el paso del tiempo.

La información sobre la inversión para la puesta en marcha de centros de atención a la dependencia (incluyendo construcción y equipamiento) en Cantabria varía de unos centros a otros. De hecho, a escala nacional, la información existente sobre el volumen de dicha inversión también difiere de unos estudios a otros. Así, se dispone de las siguientes referencias:

- Centro Europeo de Empresas e Innovación de Navarra (2003): 36.000-60.000 euros/plaza (sin contar el suelo).
- Magariño (2006): 48.000-75.00o euros/plaza.

- BIC Galicia (2008): 10.000 euros/plaza6

- Deloitte (2006): 56.199 euros/plaza (sin contar el terreno).

- Consulta a expertos del sector en Cantabria (2008).

En Cantabria, el análisis de los 60 centros que facilitaron información nos permite extraer una serie de conclusiones:

${ }^{6}$ De acuerdo con BIC Galicia (2008) en 2006, la inversión necesaria para la puesta en marcha de residencias geriátricas para 50 plazas ascendía a $497.548 €$, lo que equivalía a unos 10.000 euros por plaza. 
- El 8,3\% de los centros no realizó ningún desembolso por la inversión en inmuebles o equipamiento, ya que lo tenían arrendados.

- El 16,6\% de los centros desempeñaban su actividad en inmuebles arrendados, evitando así la mayor inversión inicial que requieren estos centros, aunque sí realizaron la inversión en equipamiento.

- El valor medio de inversión en edificación y equipamiento ${ }^{7}$ (sin incluir terrenos) de los centros residenciales en Cantabria es de 39.700,33 euros/ plaza y el valor medio para los centros de atención diurna o nocturna es de 28.795,01 euros/plaza. Sin embargo, la alta desviación típica observada para este valor de inversión pone de manifiesto la complejidad y diversidad del sector; además, cabe señalar la existencia de una amplia horquilla entre el valor mínimo y máximo de dicha inversión.

Asimismo, se deben señalar al menos tres particularidades:

- Los centros religiosos presentan una inversión en inmuebles reducida o nula y, por lo tanto, para el cálculo de estos valores de inversión se han eliminado de la muestra, lo que no excluye que, en el modelo de costes, se les considere de igual manera que a los demás centros, ya que el inmueble destinado a este servicio supone un coste de oportunidad, al no poder ser destinado a otra actividad o a su venta.
- Los centros que ofrecen varios servicios a la vez, como servicio residencial o de día, pueden estar compartiendo la inversión en inmuebles y equipamiento, la cual estará imputada a uno de los servicios y, por lo tanto, se infravalora la inversión necesaria para poder ofrecer los servicios de manera independiente.

- La variabilidad en la inversión en inmuebles y equipamiento por plaza puede estar justificada por las distintas necesidades de superficie por usuario que precisan los centros residenciales y los centros de atención diurna o nocturna. Por lo tanto, con el ánimo de homogeneizar lo máximo posible las empresas del sector para poder construir un modelo único de costes, parece necesario realizar los siguientes pasos:

1. Calcular la inversión en inmuebles y equipamiento por metro cuadrado. La Tabla 4 muestra los valores de esta inversión obtenidos del cuestionario.

Estos costes parecen reducidos si tenemos en cuenta la información publicada por el Boletín Económico de la Construcción (2008), que situaría el coste aproximado de construir esta tipología de centros en $1.545 € / \mathrm{m}^{2}$.

2. Establecer una hipótesis sobre los metros cuadrados por usuario que precisa el centro para ofrecer sus servicios.

Tabla 3. Inversión en edificación y equipamiento, por tipo de atención ( $€ /$ plaza)

\begin{tabular}{|c|c|c|c|c|c|}
\hline Tipo de centro & № de centros & Media & Desv. típ. & Mín. & Máx. \\
\hline Atención residencial & 15 & $39.700,32$ & $21.701,63$ & $5 \cdot 579,16$ & $103.576,56$ \\
\hline Atención diurna o nocturna & 11 & $28.795,01$ & $20.413,44$ & $7 \cdot 576,02$ & $72.853,20$ \\
\hline Total & 26 & $35.086,54$ & $21.461,83$ & $5 \cdot 579,16$ & $103.576,56$ \\
\hline
\end{tabular}

Fuente: Elaboración propia.

Tabla 4. Inversión en inmuebles y equipamiento (€/m2)

\begin{tabular}{l|c|c|c|c}
\hline Tipo de centro & № de centros & Media & Desv. típ. & Mín. \\
\hline Atención residencial & 15 & $1.182,21$ & 607,43 & 281,67 \\
\hline Atención diurna o nocturna & 11 & $1.142,03$ & 551,52 & 478,42 \\
\hline Total & 26 & $1.165,21$ & 573,33 & 281,67 \\
\hline
\end{tabular}

Fuente: Elaboración propia.

7 Para calcular este valor se ha considerado el deflactor del PIB en base 2008 , de manera que se puedan agregar las inversiones realizadas por los centros en años anteriores. 
El valor medio de la superficie construida por usuario de atención residencial en Cantabria, que tiene un valor de $34,42 \mathrm{~m}^{2}$, se acerca al observado en el estudio de Deloitte (2006), que considera 13 comunidades autónomas (sin incluir Cantabria) y ofrece un valor de $40 \mathrm{~m}^{2}$. Por su parte, el Centro Europeo de Empresas e Innovación de Navarra (2003) establece un espacio recomendado por usuario en atención residencial de en torno a los $20 \mathrm{~m}^{2}$, lo que se aproxima a la superficie mínima observada en la muestra de Cantabria, que asciende a 19,80 $\mathrm{m}^{2}$ /usuario.

El estudio de Montserrat (2005), que analiza ocho residencias en diferentes comunidades autónomas, muestra una superficie por usuario de entre $25,95 \mathrm{~m}^{2}$ y $57,81 \mathrm{~m}^{2}$ (la media estaría alrededor de $50 \mathrm{~m}^{2}$ ), un valor elevado teniendo en cuenta las recomendaciones, lo observado en los centros analizados en Cantabria y los requisitos materiales que establece la Orden EMP/68/2008, de 27 de agosto, para los Centros de Servicios Sociales Especializados de la Comunidad de Cantabria, que fija:

- Para centros de atención diurna, una superficie mínima útil de $7 \mathrm{~m}^{2}$ por plaza.

- Para centros residenciales, una serie de exigencias de superficie mínima y de reparto del espacio. Para establecer una referencia, se han planteado dos supuestos, según el numero de plazas del centro, y se han considerado los requisitos que plantea la Orden para centros de nueva creación con la mitad de la plazas de uso individual y una superficie para cocina equivalente a la exigida si el servicio de cocina se realiza en el centro:

- En el supuesto de una residencia de 50 plazas, se ha obtenido un valor de 16,3 $\mathrm{m}^{2}$ útiles por plaza, considerando los valores mínimos exigidos en cada dependencia y sin incluir pasillos 0 distribuidores.

- En el supuesto de una residencia de 100 plazas, se ha obtenido un valor de 15,6 $\mathrm{m}^{2}$ útiles por plaza, considerando los valores mínimos exigidos en cada dependencia y sin incluir pasillos 0 distribuidores.

Por lo tanto, en el modelo de costes se considerará como superficie los valores medios observados para Cantabria, dado que se ajustan a las medias y recomendaciones de otros estudios y están por encima de las exigencias que marca la Orden para centros de nueva construcción:

- Para atención residencial: 34,42 $\mathrm{m}^{2} /$ plaza.

- Para atención diurna o nocturna: $13,91 \mathrm{~m}^{2} /$ plaza.
3. Con las dos magnitudes anteriores, realizar una hipótesis sobre el coste de inmuebles y equipamiento.

Coste de inmuebles y equipamiento por plaza $=$ Superficie construida por usuario $x$ Coste $m^{2}$

Se plantean dos hipótesis en función de que se trate de un centro de atención residencial o un centro de atención diurna o nocturna, y dentro de cada hipótesis, se plantean dos situaciones, en función del coste por metro cuadrado considerado (bien el suministrado por las empresas encuestadas o bien el extraído del Boletín Económico de la Construcción), como refleja la Tabla 5.

Tabla 5. Coste total de inmuebles y equipamiento por plaza

\begin{tabular}{l|c|c}
\cline { 2 - 3 } & $\begin{array}{c}\text { Atención } \\
\text { residencial }\end{array}$ & $\begin{array}{c}\text { Atención diurna o } \\
\text { nocturna* }\end{array}$ \\
\hline $\mathrm{m}^{2} /$ plaza & $34,42 \mathrm{~m}^{2}$ & $13,91 \mathrm{~m}^{2}$ \\
\hline Supuesto $\mathbf{1}^{\star *}$ & $1.182,21 €$ & $1.142,03 €$ \\
\hline Coste $\mathrm{m}^{2}$ & $40.691,67 € /$ plaza & $15.885,64 € /$ plaza \\
\hline Coste total & $1.545,00 €$ & $1.492,47 €$ \\
\hline Supuesto $\mathbf{2}^{\star * *}$ & \multicolumn{3}{|c}{} \\
\hline Coste $\mathrm{m}^{2}$ & $53.178,9 € /$ plaza & $20.760,25 € /$ plaza \\
\hline Total
\end{tabular}

* El coste de construcción y equipamiento por metro cuadrado de estos centros es un 3,4\% inferior al de los centros residenciales, como se desprende de la información suministrada por los centros encuestados en Cantabria. ${ }^{\star \star}$ Cuestionario. ${ }^{* \star \star}$ Boletín Económico de la Construcción.

Fuente: Elaboración propia.

Esta inversión inicial es imputable al coste por plaza que asume el centro a través de la amortización. Puesto que no se amortizan al mismo ritmo los inmuebles que los equipamientos, resulta necesario conocer la estructura que, por término medio, presenta dicha inversión inicial.

Los inmuebles, junto con sus reparaciones y mantenimiento, y las infraestructuras suponen el 90,93\% de la inversión inicial en centros residenciales, siendo la inversión en equipamientos médicos y mobiliario del 9,07\%. En el caso de centros de asistencia diurna o nocturna, los inmuebles suponen el 94,74\% de la inversión inicial, y la inversión en equipamientos médicos y mobiliario, el 5,26\%. El plazo de amortización considerado para los inmuebles (incluidas sus reparaciones y mantenimiento, así como las infraestructuras) asciende a 35 años, y para los equipamientos médicos y el mobiliario, a 10 años $^{8}$. Por lo tanto, teniendo

8 Para establecer el periodo de amortización de los equipamientos se ha tenido en cuenta la antigüedad de los centros y la información suministrada por los profesionales al respecto. El $73,5 \%$ de los centros analizados en Cantabria se fundaron antes de 
en cuenta las hipótesis anteriores, se establecen los siguientes costes por plaza/año en relación con la inversión inicial:

Tabla 6. Gasto en amortización a imputar al coste, por plaza y año (€/plaza/año)

\begin{tabular}{l|c|c}
\hline $\begin{array}{l}\text { Gasto en } \\
\text { amortización }\end{array}$ & $\begin{array}{c}\text { Atención } \\
\text { residencial }\end{array}$ & $\begin{array}{c}\text { Atención diurna o } \\
\text { nocturna }\end{array}$ \\
\hline Supuesto 1* & \\
\hline Inmuebles & 1.057 & 430 \\
\hline Equipamientos & 369 & 84 \\
\hline Supuesto 2** & & \\
\hline Inmuebles & 1.382 & 562 \\
\hline Equipamientos & 482 & 109 \\
\hline
\end{tabular}

*Cuestionario. ** Boletín Económico de la Construcción. Fuente: Elaboración propia.

\subsection{Coste del terreno}

La inversión inicial puede requerir también un desembolso en terreno. Algunos estudios, como Deloitte (2006), han imputado este coste al coste por plaza. Sin embargo, los datos de los centros de atención a la dependencia analizados en Cantabria ponen de manifiesto una gran variabilidad tanto en los metros por plaza, que oscilan entre los $7,27 \mathrm{~m}^{2} /$ plaza y los $656,67 \mathrm{~m}^{2} /$ plaza, como en su coste por metro cuadrado, que va de los $0,21 € / \mathrm{m}^{2}$ a los $2.750 € / \mathrm{m}^{2}$. A la vista de los datos, se ha optado por no imputar este coste al coste por plaza, ya que, si bien el terreno en propiedad para ubicar un centro implica un coste de oportunidad al no poder destinar dicho terreno a otra actividad, también se revaloriza con el tiempo.

\section{Costes fijos y variables}

Dentro de los costes anuales de la actividad, se incluyen los desembolsos necesarios para el ejercicio de la actividad incluso si no hubiera clientela. Este concepto engloba tanto los costes variables (los que dependen del volumen de ocupación) como los fijos (los que son independientes de aquél). Por ello, habrá que fijar previamente el nivel de ocupación de los centros en Cantabria, para pasar a continuación a determinar los distintos costes imputables al coste por plaza.

2000, lo que supone en muchos casos la necesidad de renovación de los equipos obsoletos, con el consiguiente coste. De hecho, el $78 \%$ de los expertos encuestados consideraban que el tiempo aproximado de renovación de equipamiento informático estaba comprendido entre 6 y 9 años. Por lo que respecta a la renovación de equipos de rehabilitación física, el 71,4\% establecía un plazo de entre 6 y 9 años, y para la renovación de equipos de rehabilitación cognitiva, el 51,2\% de los expertos situaba el tiempo de amortización entre 1 y 3 años, y el $41,4 \%$ lo fijó entre 6 y 9 años. Por lo tanto, un plazo de 10 años de amortización para el equipamiento parece bastante adecuado, dada la información, y, en cualquier caso, al ser un poco superior al plazo establecido por la mayoría de los profesionales, infravaloraría el coste por plaza.

\subsection{Nivel de ocupación de los centros}

Para calcular el coste que supone una plaza por día, debería considerarse el índice de ocupación del centro, ya que si las plazas no se ocupan en su totalidad, los costes fijos se mantienen inalterados, pero los costes variables se modifican. El porcentaje de ocupación se encuentra disponible para 27 de los 68 centros analizados, y oscila entre el $56 \%$ y el $100 \%$ de ocupación, siendo únicamente un centro el que presenta el $100 \%$ de ocupación. La media de ocupación de los centros se sitúa en el 92,69\%, con una desviación típica del $11,18 \%$. Con estos datos, se plantea la hipótesis de una ocupación del $93 \%$, con lo que se aplicará un coeficiente reductor a los costes variables.

\subsection{Coste de personal}

Los costes de personal pueden variar según el convenio al que el centro esté adscrito. En Cantabria, la tipología de centros de atención a la dependencia permite distinguir tres tipos de convenio: el Convenio Colectivo del Sector de Establecimientos Sanitarios Privados de Hospitalización de Cantabria (2009), el XII Convenio Colectivo General de Centros y Servicios de Atención a Personas con Discapacidad (2006) o el V Convenio Colectivo Marco Estatal de Servicios de Atención a Personas Dependientes y Desarrollo de la Promoción de la Autonomía Personal (2008).

El porcentaje que representa el coste de personal dentro de la estructura de costes de los centros de atención a la dependencia varía de unos estudios a otros. Así, mientras Deloitte (2006) establece porcentajes de entre el $50 \%$ y el $63 \%$ (dependiendo de la comunidad autónoma), Montserrat (2005) establece un porcentaje del 70\%, Indescat (2002) lo establece en 63,2\%, el Centro Europeo de Empresas e Innovación de Navarra (2003) en el 56\%, y BIC Galicia (2008) en el $40 \%$.

En el caso de Cantabria, los centros encuestados ofrecen información variada, ya que una vez calculado el porcentaje que representan los costes de personal sobre el total de los costes asumidos, los valores oscilan entre el $10 \%$ (es el caso de algunos centros religiosos) y el $80 \%$. Por ello, la búsqueda de criterios e hipótesis que permitan homogeneizar este coste parece necesaria para poder elaborar el modelo de costes.

\subsubsection{Número de trabajadores y colaboradores externos en los centros de atención a la dependencia en Cantabria}

El 62,7\% de los centros encuestados disponen de colaboradores externos, entendiendo por éstos a los profesionales que prestan sus servicios a la residencia bien de forma periódica (por horas a la semana) o bien de forma puntual. El $95 \%$ de los centros analizados cuentan con entre uno y cuatro colaboradores. La dedicación de los colaboradores externos varía 
en función de los centros, siendo por término medio de 7,66 horas/semana/colaborador (mínimo de 0,33 horas, máximo de 36,38 horas). Asimismo, existe una gran dispersión en cuanto al coste/hora del colaborador externo, que varía entre los 5,59 €/hora y los $77,35 €$ /hora, con un valor medio de $26,64 €$ / hora y una desviación típica de 21,12.

Para poder homogeneizar la presencia de los colaboradores externos, se ha procedido a buscar el equivalente en número de trabajadores a las horas que destinan los colaboradores en el centro. Si el convenio establece 1.792 horas de trabajo, se ha aplicado la siguiente expresión:

$N$ o de trabajadores $=\stackrel{N \text { o horas semanales de los colaboradores }}{*} 52$ equivalente al año $=\frac{1.792}{2}$

La magnitud obtenida al aplicar la expresión varía desde los 0,03 a los 3,17 trabajadores equivalentes. A fin de calcular los costes de personal de una manera homogénea para todos los centros, el número de trabajadores se ha ajustado para obtener un número de trabajadores equivalentes al año. Para ello, se ha tenido en cuenta el número de trabajadores equivalente (obtenido de los colaboradores), el número de trabajadores a tiempo parcial (a los que se les da un valor del 50\%) y el número de trabajadores a tiempo completo.

Una vez calculado el número de trabajadores equivalentes se ha calculado la ratio de plazas por trabajador. De acuerdo con este cálculo, se observa una mayor necesidad de personal (menor ratio) en los centros residenciales (Tabla 7) y en los centros que atienden a personas con mayor nivel de grado de dependencia (Tabla 8), lo que incrementará, por lo tanto, los costes salariales.

Tabla 7. Ratio de plazas por trabajador equivalente, según tipo de centro

\begin{tabular}{l|c|c|c|c|c}
\hline Tipo de centro & $\begin{array}{c}\text { № } \\
\text { centros }\end{array}$ & Media & Desv. típ. & Mín. & Máx. \\
\hline Residencia & 36 & 2,16 & 0,57 & 1,02 & 3,60 \\
\hline $\begin{array}{l}\text { Atención diurna o } \\
\text { nocturna }\end{array}$ & 30 & 4,14 & 2,24 & 1,53 & 9,38 \\
\hline Total & 66 & $\mathbf{3 , 0 6}$ & $\mathbf{1 , 8 4}$ & $\mathbf{1 , 0 2}$ & $\mathbf{9 , 3 8}$ \\
\hline
\end{tabular}

\begin{tabular}{l|c|c}
\hline \multirow{2}{*}{$\begin{array}{l}\text { Prueba de } \\
\text { Kruskal -Wallis* }\end{array}$} & Chi cuadrado & Significación \\
\cline { 2 - 3 } & 18,55 & 0 \\
\hline
\end{tabular}

* Al objeto de comparar $c$ muestras independientes, se ha llevado a cabo la prueba de Kruskal-Wallis para diferencia en $c$ medianas que se distribuye como un chi cuadrado con $c$-1 grados de libertad. Este procedimiento ha resultado ser casi tan poderoso como la prueba $F$ de análisis univariado de la varianza en condiciones apropiadas a esta última, e incluso más poderoso que el procedimiento clásico cuando sus premisas son violadas. Esta prueba muestra que la diferencia entre las muestras es estadísticamente significativa.

Fuente: Elaboración propia.
Tabla 8. Ratio de plazas por trabajador equivalente, según grado de dependencia

\begin{tabular}{l|c|c|c|c|c}
\hline $\begin{array}{l}\text { Grado de } \\
\text { dependencia }\end{array}$ & $\begin{array}{c}\text { № } \\
\text { centros }\end{array}$ & Media & Desv. típ. & Mín. & Máx. \\
\hline Moderada & 23 & 3,47 & 1,86 & 1,40 & 8,75 \\
\hline Severa & 12 & 2,79 & 1,34 & 1,02 & 6,00 \\
\hline Gran & 24 & 2,33 & 0,94 & 1,53 & 6,25 \\
\hline NS/NC & 7 & 4,70 & 3,38 & 1,78 & 9,38 \\
\hline Total & 66 & 3,06 & 1,84 & 1,02 & 9,38 \\
\hline
\end{tabular}

\begin{tabular}{|l|c|c|}
\hline \multirow{2}{*}{$\begin{array}{l}\text { Prueba de Kruskal- } \\
\text { Wallis }\end{array}$} & Chi cuadrado & Significación \\
\cline { 2 - 3 } & 5,313 & 0,070 \\
\hline
\end{tabular}

Fuente: Elaboración propia.

\subsubsection{Estructura de personal y coste imputados por plaza}

A continuación, se tiene en cuenta la estructura de personal que mantienen estas empresas, distinguiéndose las siguientes áreas de trabajo:

- Administración: recursos humanos, gestión, gerencia, administración, recepción, etc.

- Servicios generales: mantenimiento, supervisión, limpieza, cocina, lavandería, transportes, etc.

- Servicios de atención a la persona y servicios de apoyo: DUE, psicólogos, fisioterapeutas, educadores, logopedas, trabajadores sociales, auxiliares, etc.

Los datos muestran una estructura que se repite, por término medio, en la mayoría de los centros: el $78 \%$ del personal trabaja en servicios de atención a la persona; el $7 \%$, en administración; y el $15 \%$, en servicios generales.

A la vista de los datos anteriores, la ratio de atención directa de los centros de atención a la dependencia en Cantabria se calcula aplicando la siguiente expresión:

$\begin{aligned} & \text { Ratio de atención } \\ & \text { directa }\end{aligned}=\frac{1}{\text { Ratio plazas sobre trabajadores equivalentes }}{ }^{*} 52$

Los valores obtenidos figuran en la Tabla 9.

Tabla 9. Ratio de plantilla y ratio de atención directa de los centros de atención a la dependencia de Cantabria

\begin{tabular}{|c|c|c|}
\hline & $\begin{array}{l}\text { Ratio de } \\
\text { plantilla* }\end{array}$ & $\begin{array}{l}\text { Ratio de atención } \\
\text { directa }\end{array}$ \\
\hline \multicolumn{3}{|l|}{ Tipo de centro } \\
\hline Residencia & 0,46 & 0,36 \\
\hline Atención diurna o nocturna & 0,24 & 0,19 \\
\hline \multicolumn{3}{|l|}{ Grado de dependencia } \\
\hline Moderada & 0,29 & 0,23 \\
\hline Severa & 0,36 & 0,28 \\
\hline Gran dependencia & 0,43 & 0,33 \\
\hline
\end{tabular}

*Plantilla completa.

Fuente: Elaboración propia. 
Básicamente, la ratio de atención directa en las residencias se ajusta a la ratio mínima de personal establecida para plazas de asistidos en Cantabria $(0,35)$, y la observada en centros de atención diurna o nocturna, a la establecida para plazas de válidos $(0,15)$. Asimismo, se observan ratios de atención directa crecientes en función del grado de dependencia, existiendo un incremento de dicha ratio del $21,74 \%$ entre la dependencia moderada y la severa y del $43,48 \%$ entre la dependencia moderada y la gran dependencia. La exigencia de mayores ratios de atención directa con el objetivo de mejorar la calidad del servicio conllevaría un incremento de los costes salariales $\mathrm{y}$, por consiguiente, un incremento del coste de cada plaza.

Por lo tanto, para calcular el coste salarial por plaza al año, se aplicará la siguiente expresión:

\section{Ratio de atención directa x Sueldo anual que estipula el convenio de acuerdo a la categoría profesional $9+33 \%$ de Seguridad Social}

Se considerará la ratio de atención directa que se observa por término medio en cada tipo de centro ( 0,36 en residencias y o,19 en centros de atención diurna o nocturna) y a continuación se realizarán simulaciones considerando mayores ratios de atención directa, de manera que pueda cuantificarse cómo dicho incremento de personal puede afectar al coste por plaza. Asimismo, se diferenciará por grado de dependencia, teniendo en cuenta los incrementos en la ratio de atención directa comentada anteriormente.

Por lo que se refiere a los gastos en personal de administración y servicios generales, no se consideran directamente en esta categoría, puesto que en algunos casos dichos servicios se encuentran externalizados, y serán considerados dentro de otros costes de explotación contemplados en el modelo.

\subsubsection{Otros costes adicionales de personal}

En el estudio de campo, se solicitó información a los profesionales del sector sobre los costes adicionales de personal que estaban asumiendo al año y, más en concreto, sobre el coste por sustituciones, antigüedad, nocturnidad o prevención de riesgos. Se obtuvieron datos en el $81 \%$ de los casos. De los 68 centros analizados, dos no facilitaron información sobre retribuciones y uno suministró un dato erróneo. Por lo tanto, de los 65 casos válidos, se observa que, por término medio, el porcentaje que representa los costes adicionales del personal sobre los costes salariales es

9 Se considerará la revisión salarial prevista para el ejercicio 2009 de acuerdo con el V Convenio Colectivo Marco Estatal de Servicios de Atención a las Personas Dependientes y Desarrollo de la Promoción de la Autonomía Personal, que se establece en el aumento del IPC real correspondiente al ejercicio 2008, más 1,3 puntos. Puesto que a fecha de realización de este trabajo se desconocía el IPC de 2008, se consideró la previsión establecida por el Fondo Monetario Internacional del $4 \%$. de 9,44\% (con una desviación típica de 11,49\%). Con el ánimo de reducir dicha variabilidad, se eliminaron los valores extremos máximos que se encontraban básicamente en aquellos centros en los que la magnitud de sueldos y salarios resulta muy reducida, por ser centros religiosos. En este caso, el porcentaje que representan los costes adicionales sobre los sueldos y salarios asciende a 8,02\%. Por último, se eliminó del cálculo aquellos centros en los que los costes adicionales de personal eran nulos, y se obtuvo así una media del 10,10\%. Este valor resulta acorde con el estudio de Deloitte (2006), que establece un coste de antigüedad del $5 \%$ sobre el coste de personal y un coste por sustituciones del $6 \%$. Asimismo, Montserrat (2005) añade al coste de personal el $8 \%$ de gasto de personal adicional derivado de sustituciones en concepto de bajas por enfermedad, absentismo y otras circunstancias que no están programadas normalmente.

Por lo tanto, se plantea como hipótesis un incremento del $10,10 \%$ sobre los costes de personal por costes adicionales derivados de sustituciones, antigüedad, nocturnidad o prevención de riesgos, entre otros.

\subsection{Otros costes de explotación}

En este apartado se analizarán otros costes de explotación de los centros, los cuales se derivan bien de servicios realizados directamente por el centro 0 de servicios externalizados. En particular, 64 de 68 centros encuestados manifestaron tener servicios externalizados.

\subsubsection{Coste de alimentación}

El servicio de alimentación supone para el centro un coste de entre el $5 \%$ y el $10 \%$, dependiendo del tipo de centro, según la Federación Nacional de Centros y Servicios de Mayores («http://www.fnm.es`). Es un servicio que cada vez tiende más a la externalización. De hecho, en Cantabria, el 40\% (27) de los centros encuestados tienen externalizado este servicio.

De acuerdo con la empresa de catering Sant Consultores, el servicio de restauración en residencias geriátricas tiene un coste de entre 5,5 y $6,8 € /$ plaza, y en los centros de día, de entre 3,2 y 3,6€/plaza. Estos datos se ajustan a las hipótesis que se han adoptado en otros estudios, que sitúan el coste de alimentación por residente en 6,42 €/día (Deloitte, 2006).

De acuerdo con los datos sobre el coste en manutención que suministraron los centros en Cantabria el coste plaza/día es de $3 €$ para los centros de atención diurna o nocturna y de $5 €$ para los centros residenciales. Este último coste resulta inferior al establecido por las empresas de catering, lo que se justifica por el hecho de que únicamente dos centros residenciales tienen externalizado este servicio, de manera que a este coste habría que imputarle el coste del personal destinado a esta función. Además, 
se observan economías de escala que permiten reducir este coste en función del tamaño del centro.

Para homogeneizar los centros y considerar de la misma manera aquellos que tienen el servicio externalizado de aquellos que no, se utilizará el coste del servicio de restauración externalizado, aplicando un valor intermedio al rango establecido por la empresa de catering Sant Consultores para los centros de tamaño intermedio (entre 50 y 100 plazas):

- Coste de manutención para centros residenciales igual a 6,2 €/plaza/día.

- Coste de manutención para centros de atención diurna o nocturna igual a $3,4 € /$ plaza/día.

Asimismo, para tener en cuenta posibles economías de escala se aplicará una reducción a estos costes del 3,55\% para los centros con más de 100 plazas y un incremento del coste de $25,20 \%$ para los centros con menos de 50 plazas, de acuerdo con las variaciones en los costes medios de manutención que se observan en los resultados de la encuesta.

\subsubsection{Coste de mantenimiento y suministros (incluida agua y luz)}

Para establecer una hipótesis sobre la magnitud del coste de mantenimiento y suministro, se ha considerado la información válida suministrada por los centros encuestados en Cantabria, una vez eliminados los valores máximos y mínimos, con el ánimo de reducir la desviación típica del dato. El coste de mantenimiento y suministro está calculado por metro cuadrado al año, observándose un valor medio de $21,39 € / \mathrm{m}^{2}$, con ligeras variaciones en función del tamaño del centro. Destacan las economías de escala que se consiguen en los centros de mayor tamaño.

Para calcular el coste por plaza, se establecerá como hipótesis un coste de mantenimiento y suministro por metro cuadrado anual igual al valor medio observado en cada tamaño de centro $\left(23,21 € / \mathrm{m}^{2}\right.$ para centros con menos de 50 plazas, $22,75 € / \mathrm{m}^{2}$ para centros de tamaño intermedio y $15,25 € / \mathrm{m}^{2}$ para centros con más de 100 plazas), de manera que se puedan tener en cuenta las economías de escala.

\subsubsection{Coste de limpieza y lavandería}

El coste de limpieza y lavandería se ha estimado a partir de la información facilitada por los propios centros. El servicio de limpieza se encuentra externalizado en 38 centros de los 68 encuestados, y 52 centros facilitaron información sobre su coste. Una vez eliminados los valores extremos, la media del coste de limpieza asciende a 366,19 €/plaza/año, observándose una clara diferencia entre los centros residenciales y los de atención diurna o nocturna, que en el primer caso ascendía a 442,99 €/plaza/ año, y en el segundo, a $267,45 € /$ plaza/año, lo que se utilizará como hipótesis en el modelo de costes.

\subsubsection{Coste en seguros y seguridad}

De acuerdo con la información suministrada por los centros en Cantabria, el valor medio del coste en seguros asciende a 94,93 €/plaza/año, que se utilizará como hipótesis en el modelo de costes. Aunque, a priori parece observase una diferencia entre el coste asumido en este concepto al diferenciar los centros residenciales de los de atención diurna/ nocturna, la diferencia no resulta estadísticamente significativa.

\subsubsection{Costes en viajes y traslados}

El valor medio del coste en viajes, de acuerdo con la información suministrada por los centros encuestados, asciende a 75,11 €/plaza, cifra que se utilizará como hipótesis dentro del modelo.

\subsubsection{Costes en servicios de gestión}

El análisis estadístico realizado a partir de los datos aportados por los 68 centros encuestados establece un coste medio en servicios de gestión de 1.287,39 €/ plaza/año.

\subsection{Necesidad de implantar sistemas de gestión de la calidad}

La Ley 2/2007 establece la obligación de todos los centros de servicios sociales de realizar periódicamente una evaluación interna de calidad de los servicios prestados, además de la obligación de los centros residenciales que cuenten con más de cien plazas de contar con un sistema de gestión de la calidad certificado por un organismo acreditado a tal efecto. En Cantabria, el 44,1\% de los centros cuentan ya con sistemas de gestión de la calidad, y el 35,3\% lo tenían en trámites cuando se realizó este trabajo. Sin embargo, el 20,5\% de los centros analizadas carecían de sistemas de este tipo, y principalmente, la carencia se manifestaba en los centros más pequeños, aquellos con menos de 50 plazas, donde el $28,6 \%$ no los tenían implantados, o no respondían a la pregunta.

Por lo tanto, la implantación de sistemas de calidad, que repercutirán en una mayor satisfacción de los usuarios y trabajadores, incrementará el coste asumido por el centro en la prestación de sus servicios, lo que repercutirá en el precio de la atención a la dependencia. De hecho, como ya manifestaba el estudio realizado por Montserrat Guillén (2007), de la Universidad de Barcelona, las exigencias de calidad incrementaron en un $44 \%$ el precio de la atención a la dependencia (en el periodo 1999-2007), lo que supone un incremento anual acumulativo de un $4,13 \%$. Partiendo de este valor, para tener en cuenta la mejora de la calidad se aplicará un coeficiente que amplíe los costes en un $4 \%$. 


\section{Margen de beneficios}

De acuerdo con los centros encuestados en Cantabria, el margen de beneficios se sitúa, en el 54,4\% de los casos, por debajo del $15 \%$, observándose como el 32,4\% de los centros presentan pérdidas (las cuales están concentradas en los centros más pequeños, por debajo de 50 plazas), como se observa en la Tabla 10. De hecho, los centros más grandes (más de 100 plazas) son los más rentables, ya que el $58,3 \%$ de ellos presentan rentabilidades entre el $6 \%$ y el $15 \%$, mientras que en los centros de entre 50 y 100 plazas se observa una rentabilidad inferior al $5 \%$ en el $50 \%$ de los casos, lo que pone de manifiesto los costes marginales decrecientes o las economías de escala que se consiguen en los centros más grandes.

Asimismo, se distinguió la rentabilidad por tipo de centro, observándose pérdidas en un porcentaje elevado en centros de atención diurna y nocturna, los cuales son también los centros más pequeños.

Tabla 10. Margen de beneficios, según tamaño y tipo de centro (\% de centros en cada categoría)

\begin{tabular}{l|c|c|c|c|c}
\cline { 2 - 6 } & \multicolumn{3}{c|}{ Por tamaño } & \multicolumn{2}{c}{ Por tipo de atención } \\
\hline Rentabilidad & $\begin{array}{c}<\mathbf{5 0} \\
\text { plazas }\end{array}$ & $\begin{array}{c}\mathbf{5 0 - 1 0 0} \\
\text { plazas }\end{array}$ & $\begin{array}{c}>\mathbf{1 0 0} \\
\text { plazas }\end{array}$ & Residencial & $\begin{array}{c}\text { Diurna/ } \\
\text { nocturna }\end{array}$ \\
\hline$<5 \%$ & 21,4 & 50,0 & 25,0 & 32,4 & 22,6 \\
\hline $6-15 \%$ & 14,3 & 35,7 & 58,3 & 37,8 & 12,9 \\
\hline$>15 \%$ & 0,0 & 7,1 & 0,0 & 2,7 & 0,0 \\
\hline Pérdidas & 47,6 & 7,1 & 8,3 & 5,4 & 54,8 \\
\hline Otras & 4,8 & 0,0 & 0,0 & 13,5 & 9,7 \\
\hline NS/NC & 11,9 & 0,0 & 8,3 & 8,1 & 0,0 \\
\hline Total & $\mathbf{1 0 0 , 0}$ & $\mathbf{1 0 0 , 0}$ & $\mathbf{1 0 0 , 0}$ & $\mathbf{1 0 0 , 0}$ & $\mathbf{1 0 0 , 0}$ \\
\hline
\end{tabular}

Fuente: Elaboración propia.

De acuerdo con estudios previos, los márgenes alcanzados en la actividad permiten obtener porcentajes de beneficio en torno al 8-12\%, según los tipos de establecimiento (BIC Galicia, 2008). Por su parte, tanto Deloitte (2006) como el Centro Europeo de Empresas e Innovación de Navarra (2003), establecen un margen comercial en residencias de un $7 \%$. La particularidad de estos estudios es que consideran únicamente en sus análisis centros de mayores residenciales, dejando, por lo tanto, fuera de estudio los centros de discapacitados o de atención diurna/ nocturna, que sí se tienen en cuenta en este estudio.

A la vista de los datos anteriores, se considerará como rentabilidad exigida para este tipo de establecimientos un $10 \%$ sobre el coste total (un valor intermedio entre el $6 \%$ y el $15 \%$, que es donde se sitúa el 58,3\% de los grandes centros, y un valor intermedio entre $8 \%$ y $12 \%$, que es lo observado en otros estudios). Se considera la rentabilidad 'que deberían alcanzar' estas empresas, y no la que dan actualmente en Cantabria, que resulta negativa en muchas ocasiones para los centros pequeños, ya que la ausencia de rentabilidad no sería un criterio empresarial para la continuidad de los centros de atención a la dependencia.

\section{Financiación}

Las vías de financiación suelen ser la subvención oficial (10\%), la autofinanciación (30\%) y la financiación ajena (60\%), según estima BIC Galicia (2008). En Cantabria, el mismo centro utiliza varias fuentes financieras a la vez. La autofinanciación a través de los pagos de los usuarios es el medio más utilizado, seguido por la subvención oficial, las donaciones y la financiación ajena, que es utilizada en un $45,6 \%$ de los casos.

En este sentido, parece necesario considerar los costes de financiación de la inversión necesaria para la puesta en marcha del centro (que ya se definió anteriormente):

- Para los centros que utilicen la financiación ajena a fin de hacer frente a dicha inversión, los costes financieros son un coste explícito.

- Para los centros que financien la inversión con otra fuente financiera sin coste (como los recursos propios que aportan), los costes financieros son un coste de oportunidad que mide lo que se podría obtener de dicho dinero y que no se va a obtener por haberlo destinado a una actividad concreta, la puesta en marcha de un centro de atención a la dependencia.

Así, se considerará como hipótesis en el modelo de costes un coste de financiación de la inversión inicial igual a la media del euríbor a doce meses de los últimos cinco años (2004-2008), que es el 3,43\%. Este coste es un coste mínimo, ya que al euríbor habría que sumarle el diferencial que aplique cada entidad financiera.

\section{Cálculo del modelo de costes}

A partir de las variables señaladas, se procede a calcular el modelo de costes, considerando distintos escenarios según el tamaño del centro, el tipo de atención en el centro (residencial, de atención diurna o de atención nocturna), el grado de dependencia y las ratios de atención directa. Los resultados se muestran en las Tablas 11 y 12. Con el ánimo de simplificar los resultados, las tablas únicamente recogen los resultados obtenidos en el supuesto de inversión inicial más reducida (la obtenida del cuestionario), aunque los comentarios sí reflejan los resultados obtenidos bajo la hipótesis de una inversión inicial más elevada (Boletín Económico de la Construcción, 2008). 
Tabla 11. Modelo de costes para los centros de atención residencial, según grado de dependencia y ratios de atención directa (€/plaza/dia)

\begin{tabular}{|c|c|c|c|c|c|c|}
\hline \multicolumn{2}{|c|}{ Tipo de centro } & \multicolumn{5}{|c|}{ Ratios de atención directa } \\
\hline $\begin{array}{l}\text { Tamaño } \\
\text { (plazas) }\end{array}$ & Grado de dependencia & 0,36 & 0,40 & 0,45 & 0,50 & 0,55 \\
\hline \multirow{3}{*}{$<50$} & Moderada & 53,03 & 56,09 & 59,90 & 63,72 & 67,54 \\
\hline & Severa & 59,01 & 62,72 & 67,37 & 72,02 & 76,66 \\
\hline & Gran dependencia & 64,98 & 69,36 & 74,84 & 80,31 & 85,79 \\
\hline \multirow{3}{*}{$50-100$} & Moderada & 51,21 & 54,26 & 58,08 & 61,89 & 65,71 \\
\hline & Severa & 57,18 & 60,90 & 65,54 & 70,19 & 74,84 \\
\hline & Gran dependencia & 63,15 & 67,53 & 73,01 & 78,49 & 83,96 \\
\hline \multirow{3}{*}{$>100$} & Moderada & 50,15 & 53,20 & 57,02 & 60,84 & 64,65 \\
\hline & Severa & 56,12 & 59,84 & 64,49 & 69,13 & 73,78 \\
\hline & Gran dependencia & 62,10 & 66,48 & 71,95 & 77,43 & 82,91 \\
\hline
\end{tabular}

Fuente: Elaboración propia.

Tabla 12. Modelo de costes para los centros de atención diurna o nocturna, según grado de dependencia y ratios de atención directa (€/plaza/día)

\begin{tabular}{|c|c|c|c|c|c|c|}
\hline \multicolumn{2}{|c|}{ Tipo de centro } & \multicolumn{5}{|c|}{ Ratios de atención directa } \\
\hline $\begin{array}{l}\text { Tamaño } \\
\text { (plazas) }\end{array}$ & Grado de dependencia & 0,36 & 0,40 & 0,45 & 0,50 & 0,55 \\
\hline \multirow{3}{*}{$<50$} & Moderada & 28,85 & 33,43 & 37,25 & 41,06 & 44,88 \\
\hline & Severa & 32,00 & 37,58 & 42,23 & 46,87 & 51,52 \\
\hline & Gran dependencia & 35,16 & 41,73 & 47,20 & 52,68 & 58,16 \\
\hline \multirow{3}{*}{ 50-100 } & Moderada & 27,85 & 32,43 & 36,25 & 40,06 & 43,88 \\
\hline & Severa & 31,00 & 36,58 & 41,23 & 45,87 & 50,52 \\
\hline & Gran dependencia & 34,16 & 40,73 & 46,20 & 51,68 & 57,16 \\
\hline \multirow{3}{*}{$>100$} & Moderada & 27,39 & 31,97 & 35,78 & 39,60 & 43,42 \\
\hline & Severa & 30,54 & 36,12 & 40,76 & 45,41 & 50,06 \\
\hline & Gran dependencia & 33,69 & 40,27 & 45,74 & 51,22 & 56,69 \\
\hline
\end{tabular}

Fuente: Elaboración propia.

Para centros residenciales con menos de 50 plazas, se observa un coste por plaza y día de entre 53,03 $€$ y 55,57 $€$, en el caso de un grado de dependencia moderada y una ratio de atención directa de 0,36 . A medida que se eleva el grado de dependencia, lo hace también el coste, que pasa a estar entre 59,01 € y 61,55 € para la dependencia severa, y entre $64,98 €$ y $67,52 €$ para la gran dependencia (Tabla 11).

A medida que se incrementa la ratio de atención directa, aumenta también el coste por plaza, ya que los costes de personal son mayores. En la ratio de atención directa máxima considerada, que es de 0,55 , la plantilla se incrementaría alrededor de un $52 \%$, y los costes totales por plaza y día, entre un $26 \%$ y un $32 \%$ : quedarían entre $67,54 €$ y $70,08 €$ para la dependencia moderada, entre $76,66 €$ y $79,20 €$ para la dependencia severa, y entre 85,79€ y $88,33 €$ para la gran dependencia.
A mayor tamaño del centro, los costes decrecen debido a las economías de escala. Se observa una reducción en los costes por plaza de los centros residenciales de entre un $2,07 \%$ y un 3,45\% cuando el centro pasa de ser menor de 50 plazas a tener entre 50 y 100. Por su parte, la disminución en costes para los grandes centros (más de 100 plazas) se estima en entre el $1,22 \%$ y el $2,06 \%$.

En particular, en centros residenciales con entre $50 \mathrm{y}$ 100 plazas se calcula un coste por plaza y día de entre $51,21 €$ y $53,75 €$ en el caso de un grado de dependencia moderada, de entre $57,18 €$ y $59,72 €$ para la dependencia severa, y de entre 63,15 € y 65,69 € para la gran dependencia, siempre considerando una ratio de atención directa de 0,36 . El aumento de costes que se produce al incrementar la ratio de atención directa se cifra entre un $27 \%$ y un $33 \%$. Así, dichos costes se sitúan entre 65,71 € y 68,25 € para la dependencia moderada, entre $74,84 €$ y $77,38 €$ para la depen- 
dencia severa, y entre $83,96 €$ y $86,5 €$ para la gran dependencia.

Para centros residenciales con más de 100 plazas, se observa un coste por plaza y día de entre $50,15 €$ y $52,69 €$ en el caso de un grado de dependencia moderada, de entre 56,12 € y 58,66 € para la dependencia severa, y de entre $62,10 €$ y $64,64 €$ para la gran dependencia, considerando en los tres casos una ratio de atención directa de o,36. El incremento de costes que se produce al elevar la ratio de atención directa es de entre un $28 \%$ y un $34 \%$; dichos costes quedan entre $64,65 €$ y $67,19 €$ para la dependencia moderada, entre $73,78 €$ y $76,32 €$ para la dependencia severa, y entre $82,91 €$ y $85,45 €$ para la gran dependencia.

En cuanto a los centros de atención diurna o nocturna con menos de 50 plazas, el coste por plaza y día oscila entre $28,85 €$ y $29,80 €$ en el caso de un grado de dependencia moderada y una ratio de atención directa de 0,19. A medida que aumenta el grado de dependencia, lo hace también el coste, que pasa a estar entre $32 €$ y $32,95 €$ para la dependencia severa, y entre $35,16 €$ y $36,11 €$ para la gran dependencia (Tabla 12).

A medida que se incrementa la ratio de atención directa, lo hace el coste por plaza, puesto que los costes de personal son mayores. En la ratio de atención directa máxima considerada, que es de 0,40, la plantilla se duplicaría, aumentando los costes totales por plaza y día entre un $54 \%$ y un $65 \%$; de esta forma, quedarían entre 44,88 € y 45,83 € para la dependencia moderada, entre $51,52 €$ y 52,47 $€$ para la dependencia severa, y entre $58,16 €$ y $59,11 €$ para la gran dependencia.

A mayor tamaño del centro, al igual que en las residencias, los costes decrecen debido a las economías de escala. Se observa una reducción en los costes por plaza de los centros de atención diurna o nocturna de entre un $1,69 \%$ y un $3,47 \%$ cuando el centro pasa de ser menor de 50 plazas a tener entre 50 y 100. Asimismo, la disminución en costes entre los centros de tamaño intermedio (50-100 plazas) y los grandes (más de 100 plazas) está entre el 0,8\% y el 1,66\%.

Los centros de atención diurna o nocturna con entre 50 y 100 plazas tendrían, según el modelo, un coste por plaza y día de entre $27,85 €$ y $28,8 €$, en el caso de un grado de dependencia moderada, de entre $31 €$ y $31,95 €$ para la dependencia severa, y de entre $34,16 €$ y $35,11 €$ para la gran dependencia, siempre con una ratio de atención directa de 0,19 . El incremento en costes que se produce al aumentar la ratio de atención directa se sitúa entre un $56 \%$ y un $67 \%$; dichos costes quedan, por tanto, entre $43,88 €$ y $44,83 €$ para la dependencia moderada, entre $50,52 €$ y $51,47 €$ para la dependencia severa, y entre $57,16 €$ y $58,11 €$ para la gran dependencia.

En los centros de atención diurna o nocturna con más de 100 plazas, se calcula un coste por plaza y día de entre $27,39 €$ y $28,34 €$ en el caso de un grado de dependencia moderada, de entre $30,54 €$ y $31,49 €$ para la dependencia severa, y de entre 33,69 € y 34,64€ para la gran dependencia, en los tres casos con una ratio de atención directa de 0,19 . El aumento en costes que deviene al incrementar la ratio de atención directa se sitúa entre un $57 \%$ y un $68 \%$; tales costes se sitúan entre $43,42 €$ y $44,37 €$ para la dependencia moderada, entre 50,06 € y 51,01 € para la dependencia severa, y entre $56,69 €$ y $57,64 €$ para la gran dependencia.

Asimismo, si comparamos los costes de la atención residencial con los de la atención diurna o nocturna, observamos en estos últimos una reducción de entre un $32 \%$ y un $46,5 \%$, principalmente motivada por los menores costes de personal asumidos y menores costes de manutención.

Por último, el interés por diferenciar dentro del coste del servicio de atención a la dependencia, los costes asistenciales, complementarios (alojamiento, alimentación o transporte) y sanitarios, llevó a calcular la estructura de costes que presentan estos centros por término medio. Para ello, se excluyeron los costes de implantación de sistemas de gestión de la calidad, los financieros y el margen de beneficios, de manera que se pudiera distinguir entre los gastos complementarios, sanitarios o asistenciales que suponen los centros de atención a la dependencia (Tabla 13).

Tabla 13. Distribución de los costes

\begin{tabular}{l|c|c}
\hline Coste & $\%$ & Consideración del gasto \\
\hline $\begin{array}{l}\text { Amortización anual por } \\
\text { plaza (inmuebles) }\end{array}$ & 6,97 & complementario \\
\hline $\begin{array}{l}\text { Amortización anual por } \\
\text { plaza (equipamiento) }\end{array}$ & 2,43 & sanitario \\
\hline $\begin{array}{l}\text { Personal de atención } \\
\text { directa }\end{array}$ & 57,99 & $\begin{array}{c}\text { sanitario } \\
\text { asistencial* }\end{array}$ \\
\hline Manutención & 14,92 & complementario \\
\hline $\begin{array}{l}\text { Mantenimiento y } \\
\text { suministro }\end{array}$ & 5,16 & complementario \\
\hline Limpieza & 2,92 & complementario \\
\hline Seguros y seguridad & 0,63 & complementario \\
\hline Viajes y traslados & 0,50 & complementario \\
\hline Servicios de gestión & 8,49 & complementario \\
\hline Total & 100,00 & - \\
\hline
\end{tabular}

* Se parte de la hipótesis de que el $80 \%$ de los gastos de personal se refieren a gastos sanitarios, ya que se trata de servicios prestados por enfermeros, psicólogos, fisioterapeutas y logopedas, mientras que alrededor de un $\mathbf{2 0} \%$ se refiere a educadores o trabajadores sociales.

Fuente: Elaboración propia.

Por lo tanto, de los costes por plaza y día que se establecieron anteriormente, se podría considerar el $39,59 \%$ corresponde a gasto complementario; el $48,82 \%$, a gasto sanitario; y el $11,59 \%$, a gasto asistencial. 


\section{Conclusiones}

Los resultados obtenidos en este estudio se añaden a los obtenidos previamente en otras investigaciones que han analizado el coste por plaza en centros de atención a la dependencia en distintas comunidades autónomas, pero sin incluir Cantabria. De acuerdo con el estudio Inforesidencias.com sobre precios de residencias geriátricas para personas mayores en 2008 , que incluye ocho comunidades autónomas, pero no Cantabria, la diferencia de precios entre comunidades autónomas llega al 45\%, lo que dificulta extrapolar los resultados observados en otras comunidades al caso de Cantabria. De ahí la necesidad y utilidad de la información recabada directamente de los centros de atención a la dependencia que operan en esta comunidad autónoma y de establecer una metodología única aplicada a distintos escenarios.

La complejidad y diversidad del sector de atención a la dependencia, ha provocado que el coste por plaza que se ha observado en otros estudios resultase muy variado. El estudio de Montserrat (2005), que analiza ocho residencias, establece costes que van desde los 28,02 euros/usuario/día para un centro a los 61,63 euros/usuario/día para otro, calculando un valor medio en torno a los 46,66 euros. Por su parte, Guillén (2007) estima el coste medio de mantenimiento para el empresario en $53 € /$ usuario/día, y según datos del Deloitte (2006), el coste actual de una plaza de residencia en España es de una media de 62,34 €/usuario/día (22.754 €/usuario/año). Además, tanto el precio como los costes dependerán del grado de dependencia, ya que, de acuerdo con Guillén (2007), si bien el precio por día de la asistencia formal-residencias y centros de día- a la dependencia fue de 41,56 $€$ en 2007, para los dependientes graves (grado III), el coste fue de 50,96 €, y para los dependientes severos, de 36,15€.

En el caso de Cantabria, en centros residenciales con una ratio de atención directa de 0,36 y menos de 50 plazas se ha observado un coste por plaza y día de entre 53,03 $€$ y 55,57 €; en el caso de un grado de dependencia moderada, el coste oscila entre 59,01 $€$ y $61,55 €$; y para la dependencia severa, entre $64,98 €$ y $67,52 €$. A medida que se incremente la ratio de atención directa, estos costes se incrementarían.

Además, las economías de escala provocan una reducción en los costes por plaza de los centros residenciales de entre un $2,07 \%$ y un 3,45\%, cuando el centro pasa de ser menor de 50 plazas a estar en un tamaño de entre 50 y 100 plazas. Asimismo, la reducción en costes para centros que pasan del tamaño intermedio (50-100 plazas) al grande (más de 100 plazas) está entre el 1,22\% y el 2,06\%.

Para centros de atención diurna o nocturna con una ratio de atención directa de 0,19 y menos de 50 plazas, se observa un coste por plaza y día de entre el $28,85 €$ y $29,80 €$ en el caso de un grado de dependencia moderada, de entre $32 €$ y $32,95 €$ para la dependencia severa, y de entre $35,16 €$ y $36,11 €$ para la gran dependencia. Las economías de escala permiten reducciones en costes de entre el 1,69\% y el 3,47\% cuando el centro pasa de ser menor de 50 plazas a estar en un tamaño entre 50 y 100 plazas, y de entre el $0,8 \%$ y el $1,66 \%$ para centros que pasan del tamaño intermedio (50-100 plazas) al grande (más de 100 plazas).

Actualmente, las administraciones ofrecen, de media, 45 euros diarios por plaza concertada en centros privados, lo que resulta insuficiente, a la vista de los costes por plaza asumidos en centros residenciales. Por lo tanto, el precio que el Gobierno esté dispuesto a pagar para concertar plazas en residencias privadas será clave para el éxito de la inversión en residencias y para dar cobertura al número de dependientes previsto para España, que se establece en cerca de un millón y medio de personas en $2020^{10}$.

En la misma línea se pronuncia el estudio de Inforesidencias.com (2008), al considerar que los precios que pagan las administraciones cuando conciertan plazas son un $22 \%$ inferiores a los de mercado (que establecen en 56,29 €/día para una residencia geriátrica privada), o Arcos (2007), que establece que la Administración paga una tarifa por cama concertada que no llega al $80 \%$ de su coste real. Además, si bien en el periodo 2004-2006 las tarifas pagadas por las administraciones autonómicas subieron un $12 \%$, los costes en el mismo periodo aumentaron un $16,15 \%$ (7,9\% anual acumulativo). De hecho, en los últimos años, los costes de las residencias se han incrementado de manera considerable. De acuerdo con Deloitte (2006), el incremento ha sido de un $16 \%$ entre 2005 y 2007 , lo que equivale a un $7,7 \%$ de crecimiento anual acumulativo. En este sentido, Guillén (2007) establece un crecimiento anual acumulativo constante de los costes de cuidados de larga duración del 5,3\%.

Por lo tanto, los resultados del modelo de costes planteado en este estudio deberían revisarse al alza cada año, en función del incremento previsto de dichos costes y de la ratio de atención directa que se establezca.

${ }^{10}$ Además, se plantea la necesidad de implantar medidas para reducir la lista de espera en las plazas públicas, que asciende a 100.000, solicitudes mientras existen en España 40.000 plazas privadas sin ocupar. 
(2008): Boletín Económico de la Construcción, segundo trimestre.

ARCOS, J. A. (2007): “Mesa redonda. La respuesta de las entidades financieras la Silver Economy", Sevilla, 16 de noviembre [inédito].

ARTíS, M.; et al. (2007): “Una estimación actuarial del coste individual de la dependencia en la población de mayor edad en España", Estadística Española, vol. $49, \mathrm{n}{ }^{-165}$, págs. 373-402.

BIC GALICIA (2008): Guía de actividad empresarial. Residencias de la tercera edad, Santiago de Compostela, BIC Galicia.

CAMACHO, J. A.; RODRÍGUEZ, M.; y HERNÁNDEZ, M. (2008): “El sistema de atención a la dependencia en España: evaluación y comparación con otros países europeos", Cuadernos Geográficos, vol. 42, no 1, págs. 37-52 [khttp://www.ugr.es/ cuadgeo/ docs/articulos/042/042-002.pdf〉].

CANTABRIA (2009): “Resolución disponiendo la inscripción en el registro, y publicación del Convenio Colectivo del Sector de Establecimientos Sanitarios Privados de Hospitalización de Cantabria, años 2008 a 2009", Boletín Oficial de Cantabria, no 46, 9-3-2009. págs. 3.4283.434 [shttp://boc.cantabria.es/boces/ verAnuncioAction.do?idAnuBlob=147415'].
- (2008): “Orden EMP/68/2008, de 27 de agosto, por la que se regulan los requisitos materiales y funcionales de los Centros de Servicios Sociales Especializados de la Comunidad de Cantabria", Boletín Oficial de Cantabria, no 172, 4-9-2008, págs. 12.159-12.171 [<http:// boc.cantabria.es/boces/verAnuncioAction. do?idAnuBlob=138349>].

- (2007): “Ley 2/2007, de 27 de marzo, de Derechos y Servicios Sociales", Boletín Oficial de
Cantabria, no 66, 3-4-2007. págs. 4.6684.691 [rhttp://boc.cantabria.es/boces/ verAnuncioAction.do?idAnuBlob=113657〉].

CENTRO EUROPEO DE EMPRESAS E INNOVACIÓN DE NAVARRA (2003): El inversor privado llama a la puerta de las residencias de ancianos, Noáin, Centro Europeo de Empresas e Innovación de Navarra [<http://nuevo.cein. es/web/es/agendanoticias/resumen/ emprendedores/2003/02/04/487.php〉].

DELOITTE (2008): Perspectivas de futuro de los servicios de atención a la dependencia. El Servicio de Atención a Domicilio (SAD) Estudio del marco conceptual, oferta, demanda y modelo de costes.

- (2006): Actualización del estudio Perspectivas de futuro de los recursos de atención a la dependencia. El sector residencial.

ESPAÑA (2012): “Real Decreto-ley 20/2012, de 13 de julio, de medidas para garantizar la estabilidad presupuestaria y de fomento de la competitividad", Boletín Oficial del Estado, no $-168,14-7-2012$. págs. 50.428-50.518 [khttp://www.boe.es/boe/dias/2012/07/14/ pdfs/BOE-A-2012-9364.pdf)].

- (2008): “Resolución de 26 de marzo de 2008, de la Dirección General de Trabajo, por la que se registra y publica el V Convenio Colectivo Marco Estatal de Servicios de Atención a las Personas Dependientes y Desarrollo de la Promoción de la Autonomía Personal”, no 79, Boletín Oficial del Estado, 1-4-2008. págs. 18.281-18.305 [<http://www.boe.es/boe/dias/2008/04/01/ pdfs/A18281-18305.pdf >].

- (2008): “Resolución de 24 de marzo de 2008, de la Dirección General de Trabajo, por la que 
se registra y publica la revisión salarial y las tablas salariales definitivas para el año 2007 del XII Convenio Colectivo General de Centros y Servicios de Atención a Persona con Discapacidad", Boletín Oficial del Estado, no 84, 4-4-2008. págs. 18.999-19.000 [khttp:// www.boe.es/boe/dias/2008/04/07/pdfs/ A18999-19000.pdf >].

- (2007): "Real Decreto 614/2007, de 11 de mayo, sobre nivel mínimo de protección del Sistema para la Autonomía y Atención a la Dependencia garantizado por la Administración General del Estado", n- 114, Boletín Oficial del Estado, 12-5-2007. págs. 20.601-20.602 [khttp://www. boe.es/boe/dias/2007/05/12/pdfs/A2060120602.pdf>].

- (2007): "Resolución de 23 de mayo de 2007, del Instituto de Mayores y Servicios Sociales, por la que se hace público el acuerdo de Consejo de Ministros, por el que se aprueba el marco de cooperación interadministrativa y criterios de reparto de créditos de la Administración General del Estado para la financiación del nivel acordado, previsto en la Ley 39/2006, de 14 de diciembre, de Promoción de la Autonomía Personal y Atención a las Personas en Situación de Dependencia", Boletín Oficial del Estado, no 132 , 2-6-2007. págs. 24.212-24.218 [<http:// www.boe.es/boe/dias/2007/06/02/pdfs/ A24212-24218.pdf〉].

- (2006): “Ley 39/2006, de 14 de diciembre, de Promoción de la Autonomía Personal y Atención a las Personas en Situación de Dependencia, Boletín Oficial del Estado, no2 299, 15-12-2006, págs. 44.142-44.156 [ [rhttp://www.boe.es/boe/ dias/2006/12/15/pdfs/A44142-44156.pdf)].

- (2006): “Resolución de 5 de mayo de 2006, de la Dirección General de Trabajo, por la que se dispone la inscripción en el registro y publicación del XII Convenio Colectivo General de Centros y Servicios de Atención a Personas con Discapacidad", Boletín Oficial del Estado, n- 152, 27-6-2006, págs. 24.225-24.245 [<http://www.boe.es/boe/dias/2006/06/27/ pdfs/A24225-24245.pdfs].

GUILLÉN, M. (2007): Estudio sobre el desembolso que supone los cuidados de larga duración (CLD) para los ciudadanos, Barcelona, Universidad de Barcelona.

INDESCAT (2002): Estadística económica dels establiments d'atenció social a la gent gran.

INFORESIDENCIAS (2008): Estudio Inforesidencias.com sobre precios de residencias geriátricas para personas mayores.

MAGARIÑO, J. F. (2006): “Las residencias seducen a inversores ajenos al sector", Cinco Días, 20-5-2006.

MONTSERRAT, J. (2005): Coste de las residencias asistidas de mayores, Barcelona, SQL [<http://www. imserso.es/InterPresent2/groups/imserso/ documents/binario/costeramayores.pdf $>$ ].

- (2003): "El coste de la dependencia”, Revista Multidisciplinar de Gerontología, vol. 13, nํㅜ 3, págs. 194-200 [<http://www.nexusediciones. com/pdf/gero2003_3/g-13-3-008.pdf >]. 